SECTION 9. Chemistry and chemical technology.

Kovalenko Marina Viktorovna

Associate Professor, Ph.D.,

Saint Petersburg State Technological University of Plant Polymers, Russia

e-mail: marina_kov@mail.ru

Sibaeva Alfia Rizayevna

Student of Chemical Technology Department

Saint Petersburg State Technological University of Plant Polymers, Russia

\title{
COMPARATIVE ANALYSIS OF THE SORPTION CAPACITY OF LARCH AND PINE WOOD PULP SAMPLES
}

Abstract: The comparative analysis of pine and larch pulp samples was carried out. The samples' testing was conducted in accordance with the Scandinavian standard SCAN - C 62: 00 .

Key words: tissui, paper, pulp, larch pulp, pine pulp, water retention value.

\section{СОПОСТАВИТЕЛЬНЫЙ АНАЛИЗ СОРБЦИОННОЙ СПОСОБНОСТИ ОБРАЗЦОВ ЦЕЛЛЮЛОЗЫ ИЗ ДРЕВЕСИНЫ ЛИСТВЕННИЦЫ И ОБРАЗЦОВ ЦЕЛЛЮЛОЗЫ ИЗ ДРЕВЕСИНЫ СОСНЫ}

\begin{abstract}
: Проведен сопоставительный анализ образияов сосновой $u$ лиственничной иеллюлозы. Испытания данных образиов проводились в соответствии со скандинавским стандартом SCAN - C 62: 00.
\end{abstract}

Ключевые слова: санитарно-гигиеническая бумага, волокнистые полуфабрикаты, лиственничная целлюлоза, сосновая целлюлоза, водоудержание.

\section{Введение}

Производство целлюлозы для санитарно-гигиенических изделий (СГИ) из древесины лиственницы становится все более актуальной темой для целлюлознобумажной промышленности. Из тонны древесины лиственницы можно получить 300400 кг целлюлозы. Это означает, что промышленный выпуск такой целлюлозы сможет кардинально изменить существующий рынок санитарно-гигиенической продукции и товаров медицинского назначения [1].

В Санкт-Петербургском государственном технологическом университете растительных полимеров совместно с ОАО «Группа «Илим» при поддержке Минобрнауки РФ разрабатывается технология комплексной переработки древесины лиственницы. В результате будут созданы новые виды волокнистых полуфабрикатов товарной целлюлозы, обладающей уникальными сорбционными свойствами, позволяющими использовать ее, в том числе и при производстве материалов санитарно-гигиенического назначения (СГИ) [2,3].

\section{Проблема}

Санитарно-гигиенические виды бумаг должны отличаться повышенной сорбционной способностью по отношению к различным жидкостям. Способность бумаги впитывать жидкость зависит как от свойств впитываемой жидкости, так и от свойств бумаги, которая эту жидкость впитывает. Процессы сорбции и адсорбции подробно рассматривалось в [4]. Главное значение при впитывании жидкости в бумаге при этом имеет взаимная связь их свойств. Ускорить прохождение воды в толщу обычной бумаги в ряде случаев можно обработкой ее поверхностно-активными 
веществами, облегчающими смачивание водой поверхности бумаги. Эти вещества можно вводить как в пропитывающий гидрофильный состав, так и на поверхность бумаги [5].

Существенное влияние на впитываемость бумаги оказывает состав волокна целлюлозы. При уменьшении лигнина и увеличении содержания альфа-целлюлозы, впитывающая способность целлюлозы увеличивается. Уменьшение содержания гемицеллюлоз в бумаге способствует увеличению впитывания, но снижает прочностные свойства. Так же благоприятное влияние оказывает фибриллированное волокно [6]. При размоле целлюлозной массы происходит набухание (гидратация), фибрилляция и укорачивание волокон, повышается их гибкость, эти процессы ведут к увеличению удельной поверхности волокна. Набухание и поглощение воды волокнистой структурой связано, прежде всего, с появлением дополнительных свободных ОН-групп на ее поверхности. Параллельно набуханию происходит образование большого количества волокнистой мелочи, а также имеет место высвобождение и растворение некоторых компонентов клеточной стенки S2 [7].

Соответственно, ставилась задача экспериментальным путем проверить гипотезу о благоприятном влиянии волокон лиственницы на сорбционную способность санитарно-гигиенической бумаги. Все исследуемые образцы были подвержены размолу до определённой степени помола [5, с. 56-57;6, с. 58-59]. Для определения морфологических характеристик волокна использовался прибор Morfi Compact. Измерение показателя водоудержания было осуществлено на лабораторной центрифуге Sigma 3-16P с использованием скандинавского стандарта SCAN - C 62: 00.

Среднеарифметическую длину волокон определяли делением общей длины всех волокон на их количество. Зависимость водоудержания образцов от среднеарифметической длины волокна имеет вид, представленный на рис. 1.

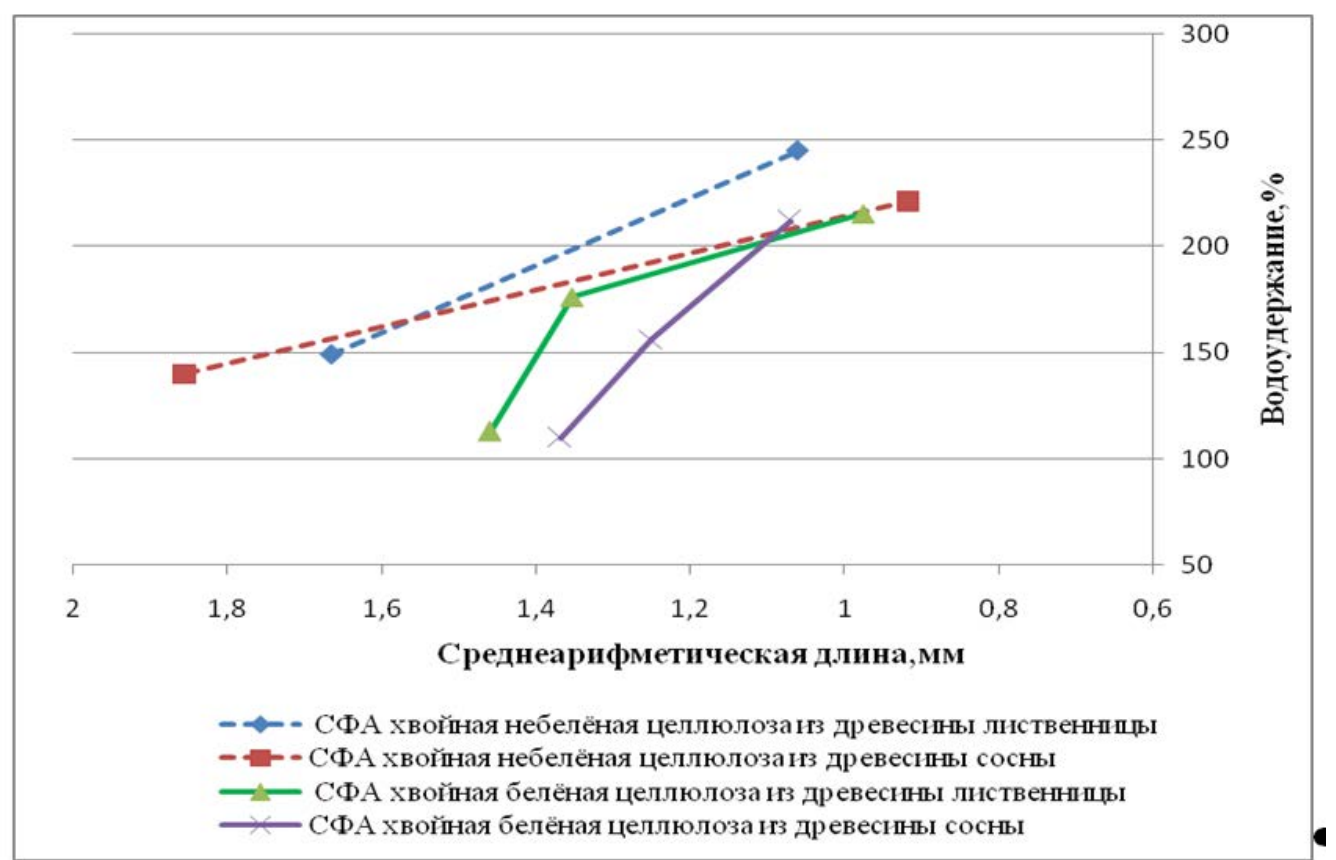

Рисунок 1 - Зависимость водоудержания от среднеарифметической длины.

Из рис.1 видно, что с уменьшением среднеарифметической длины волокна при размоле показатель водоудержания возрастает у четырех образцов. У хвойной небеленой целлюлозы из древесины лиственницы этот показатель максимальный и составляет 248\%, при изменении среднеарифметической длины от 1,06-1,66 мм. Такие 
относительно высокие показатели объясняются тем, что при размоле, волокна целлюлозы укорачиваются, фибрилируются, становятся мягче, тем самым, лучше удерживают воду.

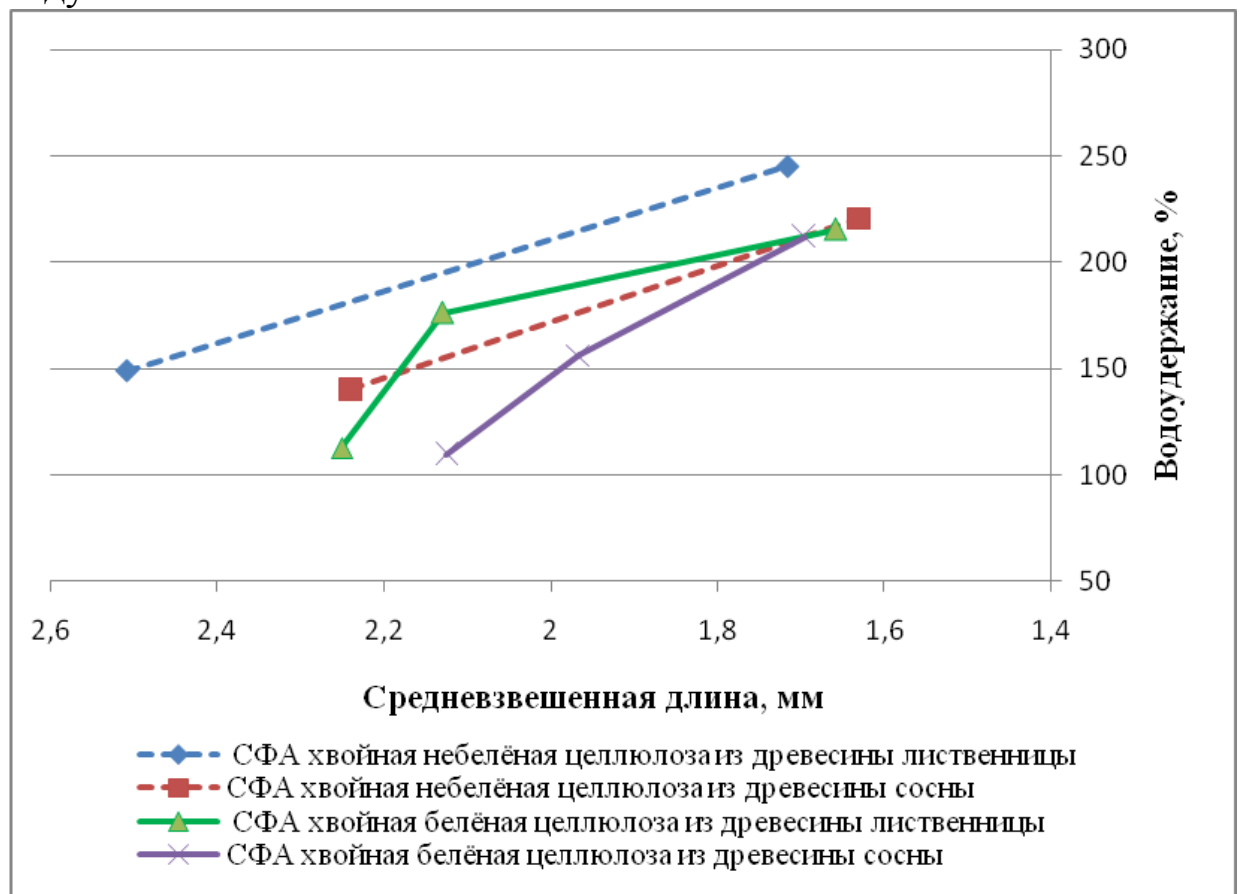

\section{Рисунок 2 - Зависимость водоудержания от средневзвешенной длины}

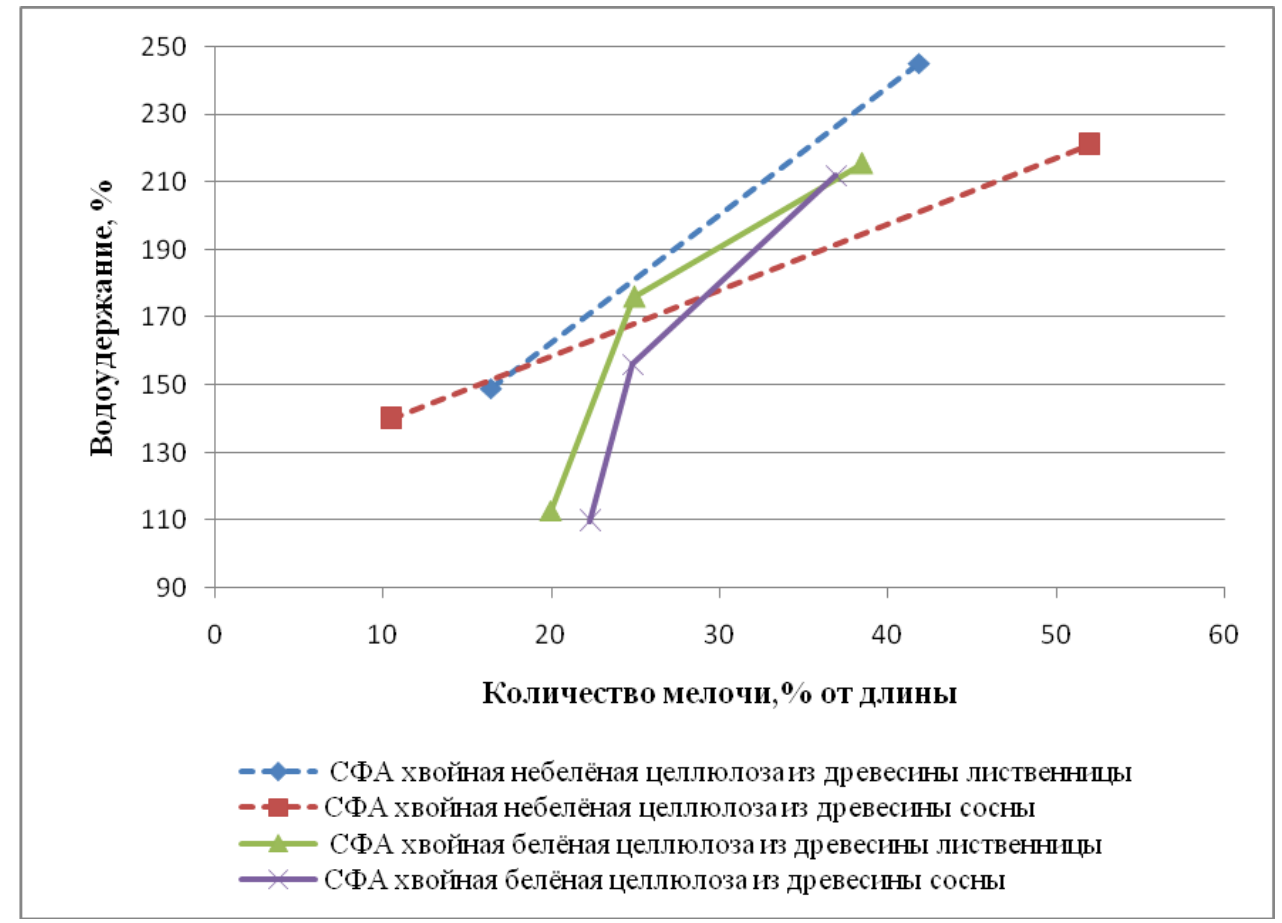

Рисунок 3 - Зависимость водоудержания от количества мелочи,\% от длины

При определении средневзвешенной длины волокна в расчет принимали массовую долю фракций с различной длиной. Зависимость водоудержания от средневзвешенной длины волокна показана на рис. 2

Из рисунка 2 видно, что с уменьшением средневзвешенной длины, показатель водоудержания возрастает у всех образцов, однако у хвойной небеленой целлюлозы из древесины лиственницы, этот показатель максимальный и составляет также 248\%. 
При определении количества мелочи в расчет принимали. на рис. 3.

Зависимость водоудержания от количества мелочи в \% от длины наглядно видна

Из рис. 3 видно, что с увеличением мелочи, водоудержание всех четырех образцов растет, что логично, так как мелочь хорошо удерживает в себе воду. Допустимое количество мелочи, содержащейся в массе целлюлозы, влияет на физикомеханические характеристики готового материала в положительную сторону. Происходит увеличение прочностных, оптических и сорбционных показателей. [10] Максимальный показатель у небеленой целлюлозы лиственницы, количество мелочи от длины в зависимости от степени помола (от 16-60ШР) варьируется от 16-51\%, что при прочих равных условиях превышает показатели для остальных образцов.

\section{Заключение}

Сульфатная хвойная целлюлоза из древесины лиственницы имеет повышенные значения показателя водоудержания, по сравнению с целлюлозой сосны. Для небеленой целлюлозы из древесины лиственницы показатель выше на 24\%, для беленой целлюлозы на 3,5\% соответственно.

\section{Литература}

1. Бычина И. «Целлюлозно-бумажная промышленность поросла лиственницей» // Коммерсантъ. 2011. №15. С. 37.

2. Проект «Лиственница». Технология сульфатной варки. Конкурентоспособность периодической и непрерывной варок в условиях реконструкции предприятий / Аким, Э.Л.; Мандре, Ю.Г.; Иванов, Ю.С.; Коваленко, М.В.; и др. // Целлюлоза. Бумага. Картон. 2011. №04. С. 52-58

3. Проект «Лиственница». Программно-аппаратный комплекс для изучения свойств древесины лиственницы / Аким, Э.Л.; Коваленко, М.В.; Рассказова, Н.Я.; Васильев, В.В.; Ерохина, О.А.; Бучельникова, Я.В.; Мандре, Ю.Г. // Целлюлоза. Бумага. Картон. 2011. №05. С. 22-26

4. Кларк, Дж. Технология целлюлозы: пер. с англ. - М.: Лесная промышленность, 1983. С. 16-17., С. 26-27.

5. Бланк, М.Г.; Матвеева, Н.А.; Фляте, Д.М. О взаимодействии химических полимеров и волокон бумаги // Проблемы сохранности документальных материалов. ЛКРД АН Л. 1977. С.87-94.

6. Производство бумаги санитарно-бытового назначения / Фролов М.В [и др.] - М.: Лесная промышленность, 1975. С. 7-10

7. Фляте, М. Свойства бумаги. - М.: Лесная промышленность, 1986. С.430-431, С 438439, С.680

8. Коваленко, М.В.; Абрамов, И.Н. Влияние размола на морфологические свойства волокна целлюлозы лиственницы // Materialy VIII Miedzynarodowej naukowipraktycznej konferencji «Naukowa przestrzen Europy - 2012». Volume 35. Nowoczesne informacyjne technologie. Fizyka. Chemia i chemiczne technologie.: Przemysl. Nauka i studia - PP. 54-58.

9. Коваленко, М.В.; Казымов, Д.С. Возможность производства полуфабрикатов высокого выхода из древесины лиственницы // Materialy VIII Miedzynarodowej naukowi-praktycznej konferencji «Naukowa przestrzen Europy - 2012». Volume 35. Nowoczesne informacyjne technologie. Fizyka. Chemia i chemiczne technologie.: Przemysl. Nauka i studia - PP. 58-61.

10. Kangas, H.; Kleen, M. Surface chemical and morphological properties of mechanical pulp fines // Nordic Pulp and Paper Research Journal. 2004. Vol. 19. No. 2. P. 191 